\title{
Territorio e identidad en las "Noticias de los campos de Buenos Aires y Montevideo para su arreglo" [1794]
}

\author{
Lucía Rodríguez Arrillaga
}

Universidad de la República, Uruguay

Resumen. "Noticias de los campos de Buenos Aires y Montevideo para su arreglo" [1794] es una obra anónima producida en un contexto intelectual y político muy preciso: el debate de utilidad pública en torno al "arreglo de los campos" (17841805). Como allí se presentan un diagnóstico y diversas propuestas para los territorios sobre los que posteriormente se configuró la República Oriental del Uruguay, la historiografía tradicional colocó esta obra en el relato nacionalista de búsqueda de los orígenes. En este trabajo, en cambio, se pretende discutir que su contenido evidencia justamente la imposibilidad que tenían los protagonistas para dar límites claros respecto a un espacio de frontera interimperial que se encontraba en proceso de configuración. También, que el discurso patriótico en torno a las potencialidades productivas del territorio que esa obra traduce da cuenta del proceso de configuración de identidades locales que adquirían sentido solo en clave imperial.

Palabras clave: "el arreglo de los campos" - Historiografía nacionalista Territorio - Patriotismo

Abstract. "Noticias de los campos de Buenos Aires y Montevideo para su arreglo" (News from the fields of Buenos Aires and Montevideo for settlement) [1794] is an anonymous work produced in a very precise intellectual and political context: the debate about the public interest regarding the "fields settlement" (1784-1805). Since it presents a diagnosis and various proposals for the territories on which later the Oriental Republic of Uruguay was set, traditional historiography placed this 
work in the nationalist narrative of the search for origins. However, the present paper argues that its contents evidence precisely the impossibility for the protagonists of giving clear limits regarding a space of interimperial border, that was in the process of configuration. Also, that the patriotic discourse on the productive potential of the territory conferred in that work realizes the configuration process of local identities which only acquired meaning in an imperial sense.

Keywords: "fields arrangement" - Nationalist Historiography - Territory Patriotism

\section{Introducción}

Como en otras partes de la América española, a fines del siglo XVIII se forjó en el Río de la Plata un pensamiento sobre el problema de cómo hacer crecer y multiplicar la riqueza regional con el cometido de contribuir al mejoramiento de la posición relativa del Imperio Español en relación a otros imperios. Específicamente, en el espacio rioplatense se elaboraron sendos informes y propuestas para dar solución al problema del "arreglo de los campos", nombre con el que se conoció el fuerte debate que entre 1784 y 1805 se tramitó acerca del ordenamiento de la explotación de tierras y ganados y la defensa de las fronteras imperiales.

El presente trabajo analiza una pieza documental elaborada en ese contexto intelectual y político en cuyo encabezamiento reza "Noticias de los campos de Buenos Aires y Montevideo para su arreglo, 1803"1; aunque fue escrita entre 1793 y $1794^{2}$ y no integra ninguno de los expedientes que se sustanciaron sobre tal

\footnotetext{
${ }^{1}$ Real Academia de la Historia, Colección Mata Linares (en adelante RAH-CML), Tomo LXXIV, pieza 9, $145 \mathrm{ff}$. La obra fue editada en dos oportunidades en base a la misma copia localizada en la RAH: BRITO STÍFANO, Rogelio, "Noticias anónimas sobre el estado de los campos de la Banda Oriental al finalizar el siglo XVIII", Revista Histórica del Museo Histórico Nacional, 1953, Nos 5254, pp. 323-516con un Estudio introductorio en pp. 301-322; MARTÍNEZ DÍAZ, Nelson, Anónimo. Noticias sobre el Río de la Plata: Montevideo en el siglo XVIII, Madrid, Historia 16, Colección Crónicas de América, 1988.

$2 \mathrm{El}$ primer editor del documento advirtió que por las referencias temporales realizadas por el autor la fecha de escritura era 1793-1794, ya que en la obra se refiere a la vigencia de 15 años del comercio libre, implementado para el Río de la Plata a partir de 1778, y también al transcurso de ciento
} 
cuestión ${ }^{3}$. Se trata de la copia de un documento anónimo que forma parte de la Colección de más de diez mil documentos que fueron acopiados por Benito de la Mata Linares y Vázquez Dávila en su carácter de funcionario de la monarquía española ${ }^{4}$ y donados por su familia a la Academia de la Historia (RAH) de Madrid en $1851^{5}$.

La obra, de 145 fojas de extensión, fue escrita por un funcionario y dirigida a un Virrey del Río de la Plata cuyo nombre no se menciona. Contiene una presentación de la geografía, la economía y la población de la Banda Norte del Río de la Plata, seguida de un extenso análisis de los principales problemas económicos e institucionales de la región y de un programa para la acción. Esas problemáticas locales fueron exhibidas desde una perspectiva imperial y vinculadas a las políticas comerciales y poblacionales seguidas por la monarquía en todo el imperio. Como

catorce años de conflictos entre España y Portugal desde que se produjo la expedición de Manuel de Lobo en 1679. BRITO STÍFANO, ob. cit., p. 301. El año 1803 del encabezamiento se explica porque en ese año Mata Linares recopiló el tomo de la CML en que se encuentran las Noticias. TAU ANZOÁTEGUI, Víctor, El taller del jurista. Sobre la Colección Documental de Benito de la Mata Linares, Oidor, Regente y Consejero de Indias, Madrid, Universidad Carlos III, 2011, pp. 9 y 92.

3 Se han localizado diversos expedientes sustanciados sobre el "arreglo de los campos". Gracias al trabajo desarrollado por el grupo Pueblos y Números del Río de la Plata se conoce la existencia de dos expedientes depositados en el Archivo General de la Nación de Argentina (AGNA) que llevan por carátula un nombre parecido, pero que fueron sustanciados en momentos distintos: "Expediente sobre el arreglo y resguardo de la campaña de este virreinato. Año 1787." AGNA, Interior, Leg. 24 Exp. 7 y "Expediente sobre el arreglo de las pampas de la otra Banda. En Buenos Aires año 1794." AGNA. Colonia, Tribunales, Leg. 144, Exp. 9. Un extracto del contenido de esos dos expedientes fue copiado por Benito de la Mata Linares cuando era regente de la Audiencia de Buenos Aires y hoy se encuentra en RAH-CML, tomo XIX. Existe otro expediente en Sevilla, Archivo General de Indias, Buenos Aires Leg. 333, que no contiene exactamente la misma documentación que los dos localizados en Buenos Aires y del cual en el Archivo General de la Nación de Uruguay se encuentra una copia fragmentaria en el tomo VI, segunda serie, de la Colección Falcao Espalter. Tradicionalmente, la historiografía se refirió a todos ellos como el "expediente sobre el arreglo de los campos", que es el título con el que está caratulado el primero que citamos.

4 Mata Linares fue oidor de la Audiencia de Chile desde 1777 y de la de Lima desde 1779, Gobernador Intendente de Cuzco desde 1784 y finalmente Regente de la Audiencia de Buenos Aires entre 1787 y 1803, en que pasó a integrar el Consejo de Indias. MARILUZ URQUIJ O, J osé, "Las memorias de los Regentes de la Real Audiencia de Buenos Aires Manuel Antonio de Arredondo y Benito de la Mata Linares", Apartado de la Revista del Instituto de Historia del Derecho de la Facultad de Derecho y Ciencias Sociales, Buenos Aires, Imprenta de la Universidad, 1949, № 1, pp. 6-7. FISHER, J ohn, El Perú Borbónico 1750-1824, Lima, IEP, 2000, p. 287. ENSINCK, Oscar Luis, "La historia argentina y los archivos españoles", Quinto Centenario, Universidad Complutense de Madrid, 1987, Vol. 12, p.165.

${ }^{5}$ Para su consulta se cuenta con un catálogo: CONTRERAS, Remedios y CORTÉS, Carmen,Catálogo de la Colección Mata Linares, 5.vols., Madrid, Real Academia de la Historia, 1970-1977. 
no se conoce la identidad del autor, que prefirió quedar en el anonimato, en reiteradas ocasiones ha sido referidapor la historiografía como el Anónimo de 1794.

Del diagnóstico y las propuestas que realizó en relación a la riqueza disponible en el Río de la Plata se desprende que, para el autor, el cambio social y económico podía alcanzarse mediante las políticas del estado corporativo de Antiguo Régimen aplicadas a las especificidades locales: impuestos, reparto de tierra, reparto de ganado, construcción de iglesias y evangelización de la campaña, entre otras. Se trataba de una estrategia de cambio social conocida para la época, porque era similar a la que se había usado para la colonización de Sierra Morena en la península6y también a la que se propuso en los otros memoriales elaborados en el Río de la Plata contemporáneamente7.

Si bien no es posible determinar de forma fehaciente la identidad del autor, por sus declaraciones y posicionamientos se sabe que era probablemente un jurista que habría arribado el Río de la Plata hacia 1787, y que posiblemente ocupaba un alto cargo, pues conocía muy bien la documentación del virreinato. La indagatoria y el estudio paleográfico de otros documentos que integran la Colección Mata Linares (en adelante CML)permitieron elaborar algunas hipótesis respecto a la autoría del documento, que aquí no se presentan por razones de espacio ${ }^{8}$. Asimismo, ello

\footnotetext{
6 Ver al respecto: GARCÍA SANZ, Ángel, "La reforma agraria de la ilustración: proyectos y resultados. El precedente del arbitrismo agrarista castellano", Ángel GARCÍA SANZ y J esús SANZ FERNÁNDEZ (coords.), Reformas y políticas agrarias en la historia de España (de la ilustración al primer franquismo), Ministerio de Agricultura, Alimentación y Medio Ambiente, Centro de Publicaciones Agrarias, Pesqueras y Alimentarias, 1996, pp. 161-200; y SÁNCHEZ SALAZAR, Felipa, "El reparto y venta de tierras concejiles como proyecto de los ilustrados", Agricultura y sociedad, Abril-J unio, 1988, № 47, pp. 123-140.

${ }^{7}$ Nos referimos a la Memoria sobre el estado rural del Río de la Plata de Félix de Azara (1801) y a la Reorganización y Plan de Seguridad Exterior de las muy interesantes colonias orientales del Río Paraguay o de la Plata de Miguel de Lastarria (1804). En ambas obras estos funcionarios proponen una batería de políticas similar a la propuesta del autor del Anónimo de 1794. Por razones de espacio aquí no se presenta el diagnóstico y las propuestas delineadas por el autor, como sí se realiza en otros trabajos.

8 En razón de que la obra se encuentra en un estado preliminar de escritura y de que la única copia conocida integra la CML, una de las hipótesis manejadas fue que el autor hubiera sido el propio Mata Linares, porque además el regente de la Audiencia compartía con el autor intereses y posicionamientos sobre varios de los temas tratados en las Noticias. Y otra de las hipótesis manejadas fue que el autor hubiera sido un funcionario que habiendo ocupado un cargo lo suficientemente cercano al regente, le hubiera facilitado la copia del documento cuando aun se
} 
posibilitó reconstruir el clima intelectual en el que fue escrita la obra y explicar las razones por las cuales fue recopilada por Mata Linares.

Las Noticias fueron tempranamente identificadas como un documento relevante para el estudio del espacio rioplatense colonial ${ }^{9}$. A partir de su primera edición por Brito en 1953, el Anónimo de 1794 fue analizado por la historiografía nacionalista tradicional desde una perspectiva que identificaba la Banda Norte del Río de la Plata como prefiguración del Estado nacional que se conformó luego del proceso de independencia. Las Noticias se transformarían así en una pieza documental de ineludible referencia para quienes se abocaron al estudio del período colonial con la preocupación de comprender las raíces agrarias de la revolución de 1811, haciendo especial énfasis en la configuración histórica del fenómeno del latifundio.

Desde mediados de la década del 1950 el Uruguay procesaba una fuerte crisis en su forma tradicional de inserción en el mercado mundial como exportador de materias primas, lo que traía aparejada una fuerte discusión sobre los modos de explotación de la riqueza y sobre la tenencia de la tierra, que tuvo entonces su traducción historiográfica. Específicamente, las Noticias aportaron a esta línea de análisis el testimonio de un contemporáneo que describía y criticaba el problema de siempre, el latifundio, y una instantánea del cuadro social derivado de ese

encontraba inacabado para su copia por tres amanuenses distintos, que es la versión que se custodia en la RAH.

9 El historiador argentino José Torre Revello fue el primer rioplatense que realizó un trabajo sistemático de relevamiento documental en la RAH, a fines de la década de 1920. El producto de ese trabajo fue un listado de documentos para el estudio de la región platense, en el cual se incluyó a las Noticias.TORRE REVELLO, José, Documentos referentes a la historia argentina en la Real Academia de la Historia de Madrid, Buenos Aires, 1929, p. 50. Fue, probablemente, a partir del trabajo de relevamiento de Torre Revello que Brito Stífano consideró la posibilidad de transcribir y editar dos de los documentos del listado. En su estudio introductorio Brito no consigna haber realizado una indagatoria mayor en la RAH que excediera el trabajo con esos dos documentos. Pero, como la sala de investigadores no se encontraba habilitada y precisó una autorización especial para poder realizar las fotografías, tendemos a pensar que contó con poco tiempo y que su trabajo se limitó a fotografiar los dos documentos que finalmente editó. BRITO STÍFANO, Rogelio, ob. cit., p. 322. La segunda pieza documental editada fue: "Papel anónimo sobre arreglo de campos guardias y ganados de la otra Banda del Río de la Plata", RAH-CML, Tomo XIX, ff. 166-171. En la nueva edición de las Noticias, Martínez Díaz actualizó el estudio introductorio, modernizó el uso del lenguaje e incluyó notas a lo largo del texto, pero en su estudio introductorio tampoco da cuenta de haber realizado una indagatoria en el fondo documental que excediera al trabajo con la propia fuente en cuestión. 
sistema de tenencia de la tierra. En ese clima intelectual no debe sorprender que Brito afirmara, a propósito del diagnóstico y las propuestas del autor del Anónimo, que "el programa podría ser valedero para el presente"10; o que Campal, luego de repasar extractos del documento, se posicionara con un "Preguntamos al lector: ¿no sería valedero este análisis para el Uruguay 1968?”11.

El fuerte interés presentista con el que se analizó el Anónimo a mediados de la década de 1950 y durante la década de 1960 y la mirada nacionalista al pasado implicaron que se olvidara historiográficamente una extensa parte del documento referida al encuadramiento del territorio rioplatense en las dinámicas imperiales y sus múltiples referencias al comercio y a la realidad metropolitana. Ello ocurrió en términos generales en el estudio introductorio de Brito y luego también con la línea interpretativa desarrollada desde Pivel Devoto en adelante ${ }^{12}$.

10 BRITO STÍFANO, Rogelio, ob. cit., p. 322.

11 CAMPAL, Esteban, Azara y su legado al Uruguay, Montevideo, Ediciones de la Banda Oriental, 1969, p. 117. Este autor es el que realiza un paralelo más extendido entre la situación que se vivía en el medio rural en su presente y la situación descripta por el autor del Anónimo en 1794: "El análisis que acabamos de transcribir, aunque se refiere a una época muy alejada de la nuestra, es totalmente válido para la situación actual del Uruguay rural. Así como los cueros del estanciero pobre, que explotaba ganado manso a costa de jornales y diezmos, no podían competir sin quebrantos para él con los muy baratos del hacendado rico obtenidos del ganado cimarrón (espontaneidad) mediante la destreza laboral de changadores y desolladores (trabajadores destajistas de alta productividad), determinando, como consecuencia, el abandono de la cría organizada -inclusive porque los peones preferían el trabajo a destajo, más remunerativo y libre que el asalariado-, del mismo modo, el actual productor rural progresista, que tecnifica su explotación en base a onerosos insumos en su mayor parte importados (maquinarias, combustibles y lubricantes, fertilizantes, herbicidas, etc.), que debe recurrir a la contratación de trabajadores más calificados y mejor remunerados, que paga impuestos más altos por unidad de superficie explotada al aumentar la productividad de la tierra (detracciones), resulta siempre derrotado, en el juego de mercado, por la competencia de los productos de bajo costo que se obtienen en base a la explotación extensiva, con bajo nivel de insumos, de la espontaneidad pastoril." Ibíd., p. 111.

12 Fue Pivel Devoto quien incluyó al Anónimo de 1794 entre los "Planes para la ordenación del medio rural", junto a la obra de Miguel de Lastarria ("Reorganización y Plan de Seguridad Exterior Colonias Orientales de las muy interesantes colonias orientales del rio Paraguay o de la Plata") y a la de Félix de Azara ("Memoria sobre el estado rural de Río de la Plata"), y junto a otros informes producidos a fines del siglo XVIII y comienzos de siglo XIX, que al igual que el Anónimo, no integraban los expedientes sobre el "arreglo". PIVEL DEVOTO, Juan E., Raíces coloniales de la revolución oriental de 1811, Montevideo, Editorial Medina, 2da. Edición, 1957, pp. 59-69. La inclusión del Anónimo de 1794 fue realizada en la segunda edición de la obra porque cuando Pivel escribió los prólogos a los tomos del Archivo Artigas que refundió luego en esa primera edición de Raíces coloniales (1952), se desconocía el contenido del Anónimo, que fue editado recién en 1953.Siguieron esta misma línea de análisis: BARRÁN, J osé Pedro y NAHUM, Benjamín, Bases económicas de la Revolución artiguista, Montevideo, Ediciones de la Banda Oriental, 1964; SALA, 
Por ejemplo, el primer editor de las Noticias entendió que era lógico que a partir de 1778 se fuera "robusteciendo y perfeccionando la idea de constituir una jurisdicción política comprensiva de toda la Banda oriental"13.En su explicación, así lo demandabanl as peculiaridades del marco geográfico, el aumento repentino de la importancia de esos territorios y el particularismo de sus intereses y problemáticas. El estudioso planteó, incluso, que las Noticias habrían captado en su "estado naciente esa realidad original en el momento en que sus factores determinantes, positivos y negativos, perfilan ya claramente a la Provincia, matriz de la República"14.

El interés capital para la edición y estudio del documento radicaba para su primer editor en esa prefiguración del espacio político nacional que de manera involuntaria había realizado el autor del Anónimo:

\begin{abstract}
"Aunque el manuscrito haya sido titulado como Noticias de los campos de Buenos Aires y Montevideo....', en realidad, dando certeramente en el blanco de uno de los grandes temas de la época virreinal, son los campos de la Banda Oriental los que acaparan la atención del autor y es su consideración tanto como la de las medidas conducentes a su 'arreglo' -término tan usado al respecto en la época- lo que constituye el verdadero asunto del trabajo"15.
\end{abstract}

De este modo, al valorar la relevancia del documento, Brito no ponderó de forma suficiente que en la época en la que escribió el autor de las Noticias no existía nada similar a la Banda Oriental como unidad política autónoma, y menos aún la Provincia Oriental que él definió como "matriz de la República". Tampoco se detuvo en que los territorios a los que hizo referencia el autor del Anónimo en esa época estaban bajo diferentes jurisdicciones políticas ${ }^{16}$. Y que por lo tanto, el título

Lucía; de la TORRE, Nelson y RODRÍGUEZ, Julio, Estructura económico-social de la Colonia, Montevideo, Ediciones Pueblos Unidos, 1967 y Evolución económica de la Banda Oriental. Montevideo, Ediciones Pueblos Unidos, 1968; CAMPAL, Esteban, Hombres, tierras y ganados, Montevideo, Talleres Gráficos, 1962 y Azara y su legado..., ob. cit.

13BRITO STÍFANO, Rogelio, ob. cit., p. 306.

14 Ibíd. p. 311.

15 Ibíd. p. 303.

16 Tal como fue apuntado por Frega "los territorios al este del río Uruguay y hasta la frontera con los dominios de Portugal no conformaban una unidad administrativa a comienzos del siglo XIX. 
puesto al documento expresa la conciencia geográfica que en esa época se tenía sobre dichos territorios, que se encontraban justamente bajo la jurisdicción de Buenos Aires y Montevideo, y en disputa con los portugueses y los administradores de los pueblos misioneros.

Mediante esa interesante operación historiográfica y gracias al título con el cual se decidió editar el documento, "Noticias anónimas sobre el estado de los campos de la Banda Oriental al finalizar el siglo XVIII", el Anónimo fue quitado de su contexto de producción y colocado en el relato nacionalista de búsqueda de los orígenes.

Esta perspectiva hizo que Brito Stífano considerara como una "larga digresión" algunas de las referencias a la realidad metropolitana que son recurrentes en las Noticias. Sin embargo, no se trataba de digresiones sino indicadores de que el autor del documento no estaba pensando el Río de la Plata, o incluso la Banda Norte de ese río, como espacio autónomo y como prefiguración de una futura República independiente. Sino que su interés era pensar el espacio económico rioplatense en el marco de las dinámicas imperiales e, incluso, en provecho de España.

Aquí se cree que la manera de presentar y representar el territorio del autor del Anónimo de 1794 se explica mejor si su análisis se inscribe en nuevas tradiciones historiográficas. Específicamente, aquellas que desde la historia política y social $^{17}$ y desde la historia económica ${ }^{18}$ han levantado los presupuestos

Por el contrario, es posible identificar por lo menos tres polos que avanzaban en la ocupación del espacio. Uno en Buenos Aires[...]; otro en la ciudad-puerto de Montevideo, sede de la Gobernación homónima y del Apostadero naval; y el tercero en los dominios lusitanos de Brasil, que consideraban el Río de la Plata como sus "fronteras naturales", FREGA, Ana, "Uruguayos y orientales: itinerario de una síntesis compleja", en J. C. CHIARAMONTE, C. MARICHAL y A. GRANADOS (comps.), Crear la nación. Los nombres de los países de América Latina, Buenos Aires, Editorial Sudamericana, 2008, p. 98.

${ }_{17}$ Gracias a los trabajos desarrollados por el equipo liderado por Frega se logró romper con el esquema interpretativo de las fronteras nacionales actuales para el estudio del pasado colonial y su crisis, y se demostró que el vocablo "orientales" en el contexto de las revoluciones de independencia no era estrictamente una referencia geográfica, sino un apelativo político que denotaba la adhesión al proyecto artiguista. El primer trabajo realizado en esa clave fue: FREGA, Ana "La constitución de la Banda Oriental como provincia. Apuntes para su estudio desde un enfoque local", Historia y 
nacionalistas para el estudio del pasado de los territorios en los que finalmente se constituyó el estado nación República Oriental del Uruguay. Lo que ha permitido discutir que la“Banda Oriental" o la "Provincia Oriental", que comienza a configurarse en 1811, no era una unidad política ni económica prefigurada por la geografía. Por ello uno de los propósitos de la investigación que sustenta este trabajo fue identificar y precisar la dimensión espacial del análisis formulado en esa obra, como forma de conocer la conciencia geográfica de un informante calificado y planificador del período.

El trabajo se estructura en torno a dos apartados. En el primero se procura discutirla interpretación nacionalista de la conciencia geográfica del autor de las Noticias y demostrar que no veía en el territorio de la Banda Norte del Río de la Plata la prefiguración de una unidad política natural. En ese primer apartado se presenta el espacio que el autor identificaba bajo la denominación "campos de Buenos Aires y Montevideo", la manera en que entendía el problema de la frontera abierta con los portugueses y, por último, el análisis de su propuesta de reforma de las jurisdicciones eclesiásticas. En el segundo apartado se procura mostrar que el discurso patriótico que se traduce en la obra en torno a las potencialidades

Docencia, APHU, 1994, №1, pp. 47-56. Productos más maduros de esa línea de investigación fueron: FREGA, Ana, "Uruguayos y orientales..." ob. cit., FREGA, Ana, Pueblos y soberanía en la revolución artiguista. La región de Santo Domingo Soriano desde fines de la colonia a la ocupación portuguesa, Montevideo, Ediciones de la Banda Oriental, 2007, que es su tesis de doctorado. ISLAS, Ariadna, "En búsqueda de fronteras perdidas. Algunas notas sobre la construcción política de las "fronteras naturales" en la región platense sobre la lectura de viejos mapas (1600 ca.- 1853)", s/ d., y más recientemente: "Límites para un Estado. Notas controversiales sobre las lecturas nacionalistas de la Convención Preliminar de Paz de 1828", Ana FREGA, (coord.), Historia regional e independencia del Uruguay. Proceso histórico y análisis crítico de sus relatos. Montevideo, Ediciones de la Banda Oriental, 2009, pp. 169-216 y FREGA, Ana, "Las fronteras de la soberanía. Apuntes para un atlas de la banda oriental del río Uruguay en la primera mitad del siglo XIX”, en J . FERNÁNDEZ SEBASTIÁN y C. SUÁREZ CABAL (eds.), La subversión del orden por la palabra. Tiempo, espacio e identidad en la crisis del mundo ibérico. Siglos XVIII-XIX, Bilbao, Servicio Editorial de la UPV, 2015, pp. 219-239.

${ }^{18}$ La línea de trabajo trazada por Moraes abandonó las fronteras nacionales modernas para el estudio de los paisajes agrarios coloniales que se configuraron en los territorios al norte del Río de la Plata y sostuvo que por las características ecológicas de esos territorios se habían conformado allí diversos paisajes agrarios y sistemas de explotación de esos recursos que se encontraban en pugna. MORAES, María Inés, Las Economías Agrarias del Litoral Rioplatense en la segunda mitad del siglo XVIII: Paisajes y Desempeño, Tesis de Doctorado, Madrid, Universidad Complutense de Madrid, 2012. Esta tesis recoge una línea de trabajo comenzada en el año 2006. 
productivas del territorio, evidencia un proceso de configuración de identidades locales que adquirían sentido solo en clave imperial.

\section{Los “campos de Buenos Aires y Montevideo": territorio, frontera y jurisdicciones}

Una de las objeciones que podría hacerse a la idea de que el autor del Anónimo captó en "estado naciente" los factores que perfilaban ya en ese momento a la Provincia Oriental podría ser el hecho de que no proporcionó marcas geográficas y referencias de distancia claras respecto del territorio sobre el que realizó su diagnóstico y propuestas. Es más, de sus declaraciones no es posible circunscribir un espacio claramente delimitado, en parte por la propia disputa que existía sobre ese territorio entre las monarquías española y lusa; disputa que se traducía en la representación del espacio.

Como la obra estaba dedicada a un nuevo virrey, el autor comenzó por delinear el espacio de jurisdicción del virreinato; sin embargo, procuraba concentrarse específicamente en los problemas y las potencialidades de la Banda Norte del Río de la Plata y no en toda la jurisdicción virreinal. Por ello, a lo largo del texto es posible encontrar dos escalas distintas en la presentación del territorio, tal como queda demostrado en los topónimos utilizados por el autor. Para la primera escala aludió a: "tierra meridional de nuestra América", "Provincia", y "Virreynato"; mientras que para designar el espacio que tenía interés en "arreglar" refirió a: "por una y otra banda del Río de la Plata", "la Banda del Norte de Buenos Ayres", "la Banda Septentrional del Río de la Plata", "Península" u "océano de tierra", y "la Campaña". En ambas escalas de presentación del territorio la marca geográfica que funcionó como uno de los principales articuladores del espacio fuela del Río de la Plata.

En cuanto a la primera escala, el autor realizó una presentación bastante extendida y poco precisa de los límites del virreinato, que incluía territorios que no habían sido incorporados plenamente al dominio español y que se encontraban en 
muchos casos habitados por indígenas no asimilados. Así ocurrió, por ejemplo, cuando el autor tuvo que delimitar la jurisdicción del virrey "a la mano derecha" del Río de la Plata:

\begin{abstract}
"A la mano derecha de el que se desembarca halla una Peninsula, prolongada hasta el Marañon provincia de las Amazonas en que se le ofrece a la vista vn espacio de mas de 400 leguas de terreno sugeto á la Corona de Castilla; bordeado del mar p. ${ }^{\mathrm{r}}$ la parte Oriental hasta el rio Grande de San Pedro; Por el Sur del Rio de la Plata; por el oeste del Rio Parana, y por el Norte del rio de la madera y tierras de la región de las Amasonas. Esta dilatadissima Peninsula encierra el criadero del ganado vacuno, cuias pieles dan materia a nuestro Comercio para vna de las mas vastas negociaciones de America, pero allí mismo tiene V.E. el cuidado de vn vecino extranjero que vela incesantemente por caer de sorpresa sobre este Llano y robarlo: y vea aquí V.E. vno de los maiores cargos que hande traer despierta su atención"19.
\end{abstract}

El límite norte indicado por el autor para el espacio de jurisdicción virreinal es el que evidencia un mayor desconocimiento de su parte respecto al poder efectivo detentado en esa región. Porque, además, la marca geográfica- el río de la Madera $^{20}$ - y la referencia de distancia proporcionadas serían contradictorias ${ }^{21}$.

19 "Noticias de los campos de Buenos Aires y Montevideo para su arreglo", RAH-CML, Tomo LXXIV, pieza 9 , f. $2 \mathrm{v}$.

Cabe aclarar que el autor refiere a la "mano derecha" de quien ingresa al Río de la Plata desde el Atlántico, y no a la margen derecha del Río de la Plata, cuyo punto de referencia es la naciente en la desembocadura de los ríos Paraná y Uruguay y correspondería, por tanto, a la costa de la actual Argentina. [NOTA DEL EDITOR]

20 El río de la Madera, afluente del Amazonas, era uno de los límites de la Gobernación de Moxos que en 1776 había sido incorporada al Virreinato del Río de la Plata. Tanto en el Tratado de Madrid de 1750 como en el San Ildefonso de 1777 ese río había sido establecido como uno de los límites entre los dominios de las coronas de España y Portugal. Se trata de los artículos VII y VIII, y de los artículos $\mathrm{X}$ y XI, de los respectivos tratados, que se pueden consultar en: http:// www.cervantesvirtual.com / obra-visor/tratado-firmado-en-madrid-a-13-de-enero-de-1750para-determinar-los-limites-de-los-estados-pertenecientes-a-las-coronas-de-espana-y-portugal-enasia-y-america--0/html/ff8d40ae-82b1-11df-acc7-002185ce6064_2.html y en:

http:// www.cervantesvirtual.com/ obra-visor/tratado-preliminar-sobre-los-limites-de-los-estadospertenecientes-a-las-coronas- de espana-y-portugal-en-la-america-meridional-ajustado-yconcluido-en-san-lorenzo-a-11-de-octubre-de-1777--0/html/ff8d38fc-82b1-11df-acc7002185ce6064 1.html

${ }^{21}$ La distancia que separa las “tierras de la Amazonas” o el río de la Madera del Río de la Plata es mayor a las 400 leguas referidas por el autor. Para la época, una legua equivalía a 6.000 varas, y la vara castellana correspondía a 83,59 centímetros, en su equivalencia con el sistema métrico decimal. Por lo tanto, 400 leguas equivalían a poco más de 2.000 kilómetros de distancia, que es una distancia insuficiente para alcanzar el mencionado río de la Madera partiendo desde el Río de la Plata. Tomamos como referencia la vara castellana porque era la que estaba vigente en Buenos 
Para el resto de los puntos cardinales los límites fueron dados de modo más específico, ya que se trataba de territorios mejor conocidos: por el este, la extensión del virreinato en la ribera norte del Río de la Plata limitaría con el río Grande de San Pedro o Laguna de los Patos; por el oeste, con el rio Paraná; y por el sur con el propio Río de la Plata 22 .

La misma imprecisión puede verse en los intentos del autor por delimitar el espacio de jurisdicción virreinal en la banda del sur del Río de la Plata, donde se valió también de marcas geográficas y de distancia que eran muchas veces contradictorias entre sí. Por el norte la jurisdicción del virreinato llegaría hasta la provincia de Puno23, "contandose desde la capital hasta aquella como 700 leguas de camino, harto molesto y arriesgado"24. Y "A la parte occidental de Buenos Ayres” tenía el virrey "bajo su mando el territorio conocido por las Pampas el qual se extiende por vn espacio de 300 leguas hasta la falda de la Cordillera de Chile"25.

En cuanto a la segunda escala, el autor restringió el territorio sobre el que iba a hablar con mayor detenimiento a la Banda del Norte del Río de la Plata. Y si bien anunció al inicio de la obra que trataría también la banda sur, no volvió luego a ahondar en los problemas de gobierno que aquejaban a esos territorios específicamente:

\footnotetext{
Aires, lugar de escritura del autor. Para las diferencias que existían entre la vara vigente en Buenos Aires y Montevideo (85,9 centímetros), y el equívoco del fiel ejecutor del cabildo de Montevideo que explica dicha diferencia ver: MORAES, María Inés,ob. cit., p. 152 y nota 469.

${ }^{22}$ Nótese que el autor no tomó al río Uruguay como referencia geográfica para delimitar lo que presentó como el territorio bajo gobierno del virrey en la ribera norte del Río de la Plata, pues esa "península de tierra" en su definición se prolongaría hasta el río Paraná como su límite más occidental.

${ }^{23}$ La Intendencia de Puno se constituyó en 1784 como un desgajamiento de la de La Paz y fue la última en quedar bajo jurisdicción del Virrey del Río de la Plata pues se sumó así a las 8 que habían sido creadas por la Ordenanza de Intendentes de 1782, y en 1796 terminaría por incorporarse al Virreinato del Perú.

24 "Noticias...", ob. cit., ff. 2v-3. Si consideramos nuevamente la extensión de la legua en relación a la vara castellana, la distancia considerada por el autor sería de unos $3.500 \mathrm{~km}$ mientras que la ciudad de Puno se encuentra actualmente a unos $3.000 \mathrm{~km}$ de la de Buenos Aires

${ }^{25}$ Ibíd., ff. 4-4v. Nótese que la distancia de trescientas leguas que separaban según el autor a Buenos Aires de la Cordillera de los Andes era una distancia aproximada y variable.
} 
“Hablaremos de esto y de todos los puntos de Gobierno respectivo á la Banda del Norte de Buenos Ayres: y después pasaremos á el continente del Sur, haciendo assi do partes del asunto en este papel; que miren á las dos porciones Austral y Meridional del territorio que va a gobernar V.E." 26.

Más avanzada la obra, volvió a precisar cuál era el territorio del cual hablaba y enumeró las escasas poblaciones que contaban con Iglesias, que eran según su punto de vista el factor civilizador por excelencia:

"Considerese el territorio de q.e hablamos, tomandolo desde Montevideo hacia el Norte vn Espacio de mas de quatrocientas leguas de largo, y de doscientas poco menos de ancho; y asiéntese por supuesto que en todo ese occeano de tierra, no hay quizás vna docena de Capillas; ni vna poblacion formal. Maldonado, las Minas, la colonia, Santo Domingo Soriano, La Vivoras, Las Piedras, el Rosario, ([Las]) Corrientes y Canelones (situados todos á la orilla del agua) son las vnicas Iglesias que se conocen hasta el paraguay, á reserba de los Pueblos de Misiones"27.

Por estas y otras afirmaciones que el autor realizó a lo largo de las Noticias ${ }^{28}$ es posible establecer que cuando refirió a una extensión de poco menos de doscientas leguas de ancho, consideraba, por un lado, la distancia entre la margen derecha del Paraná y el río Grande de San Pedro, y por el otro, la distancia entre Montevideo y la isla de Santa Catalina.

El territorio al que refirió el autor con la denominación de "Campos de Buenos Ayres y Montevideo" sería entonces el que él mismo definió como Banda del Norte del Río de la Plata, cuyos límites eran: el Río de la Plata por el sur, y el Paraná y el río Grande de San Pedro por el oeste y este, respectivamente. En cuanto al límite por el norte, vemos que en el pasaje anterior no aparece el río de la Madera sino únicamente la referencia de distancia de unas cuatrocientas leguas contadas desde Montevideo o desde el norte del Río de la Plata.

\footnotetext{
26 Ibíd., f. 5.

${ }^{27}$ Ibíd., f. 50.

28 Ibíd., f. 12v.
} 
La inexistencia de una línea por el norte para "la Campaña" que se extendía por esa Banda Septentrional del Río de la Plata fue explicitada por el autor en otro pasaje del texto, y se debía al conflicto de límites que aun permanecía abierto entre España y Portugal:

“El límite de toda ella por el ángulo del Norte á el Este está todavía en litigio entre España y Portugal. Desde la Laguna de los Patos hacia el Nordeste siguiendo la costa del mar hasta el Brasil se mira como de esta Nacion, y nada disputamos sobre este terreno, sin embargo de haber sido descubierto p.r nosotros y tomado posesión de el la Corona de Castilla en fines del siglo $15^{\prime \prime 2}$.

La imposibilidad de definir "la Campaña" por el norte da cuenta de que la frontera abierta con los portugueses llegaba a afectar la propia denominación y delimitación del territorio. En ese sentido, parecería que por el mero acto de nombrar el territorio como "Banda Norte del Río de la Plata" se lo dotara de una entidad que tenía solo de manera incipiente, si se lo considera desde el punto de vista de su ocupación efectiva por los españoles. Podría decirse, entonces, que el Anónimo aporta un ejemplo de ese proceso complejo de constitución de un espacio de frontera a partir de su denominación.

En este caso el autor usaba una referencia geográfica clara, el Río de la Plata, y se identificaba con un determinado centro de poder para realizar su nominación, Buenos Aires, que era el lugar desde el cual escribía. Solo desde allí adquiría sentido la expresión "Banda Norte del Río de la Plata". Se trataba de una operación intelectual y política muy común en la documentación de la época que expresaba "la influencia e intereses provenientes del centro político de Buenos Aires"30. Esa "Banda Norte" fue representada en este mapa de época que, si bien elaborado por otro funcionario del imperio, expresa la misma conciencia geográfica quela del autor del Anónimo.

29 “Noticias...", ob. cit., f. 13.

30 Ver: FREGA, Ana, “Uruguayos y orientales...”, ob. cit., p. 96. 
Una parte del territorio que el autor consideraba dentro de la "Banda Norte" era llamada en la documentación de la época "Provincia del Uruguay” o “Doctrinas del Uruguay"31.

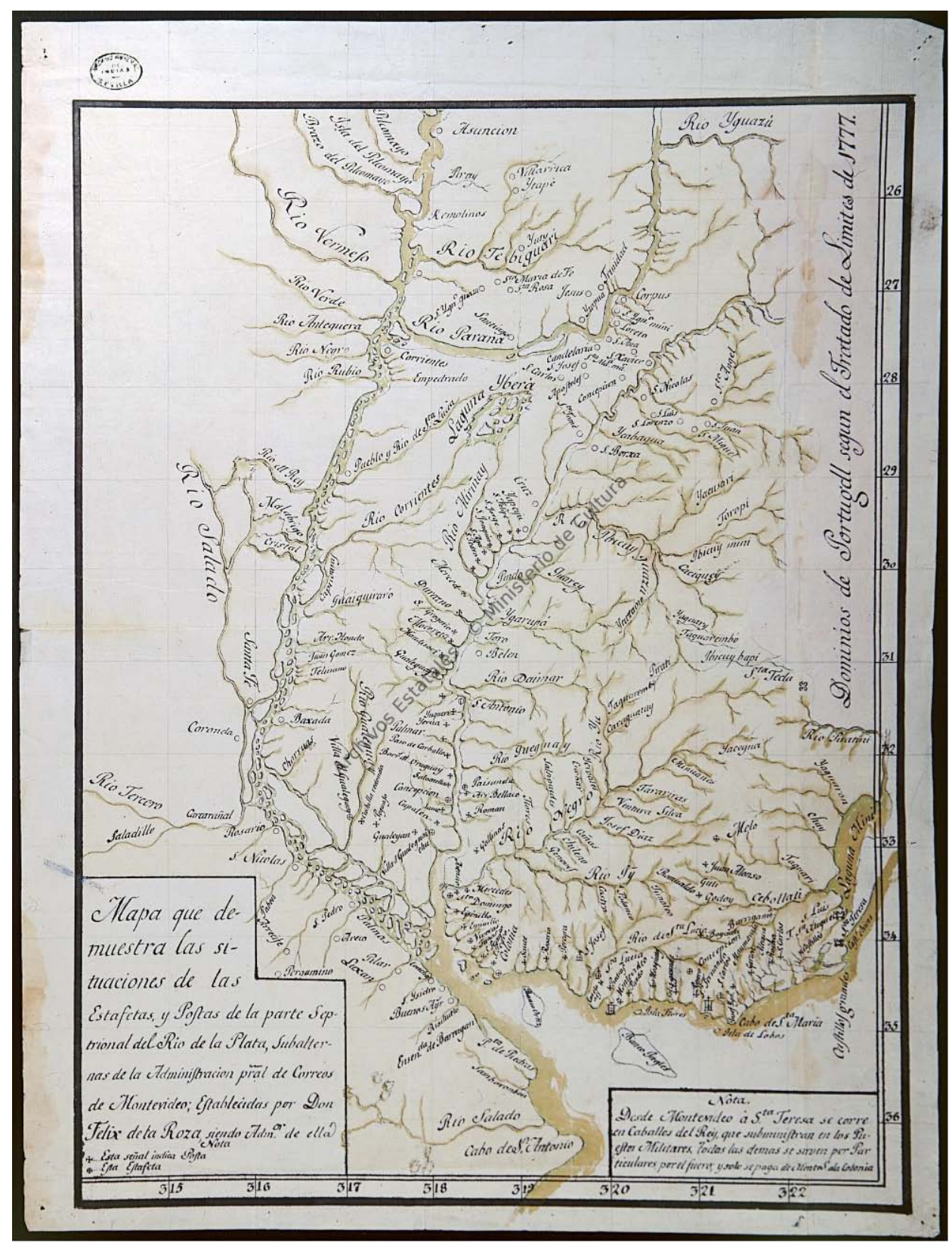

Mapa: La Banda Norte del Río de la Plata ${ }^{32}$

31Ibíd., pp. 96-97.

32 "Mapa que demuestra las situaciones de las Estafetas y Postas de la parte Septentrional del Río de la Plata Subalternas de la Administración general de Correos de Montevideo establecidas por Don 
Se trataba de una denominación muy usual sobre todo antes de que los jesuitas fueran expulsados de los territorios del alto Uruguay en 176733. La inclusión del autor podría explicarse porque él formaba parte de aquellos funcionarios que creían que los derechos de los pueblos misioneros sobre los territorios al norte del río Negro eran perjudiciales para su seguridad:

“El restante territorio, que corre á la parte vlterior del rio Yi azia el grande de S." Pedro, há estado considerado como delos Indios de Misiones; pero ni lo han poblado jamás, ni les ha sido hecha formal adjudicacion: y además de ser un terreno dilatadísimo, dista mas de 120. leguas delos Pueblos de Misiones, tomado desde el Yi: y por falta de poblacion por esta parte ha sido siempre el teatro de la guerra entre Españoles, Indios, y Portugueses á causa de que casi todo el ganado que se cria en este campo, entre los Rios Vruguay y San Pedro, es silvestre, o cimarron, sin marca ni rodeo, y el que tiene mas Dueños con todo deno pertenecer á ningun particular"34.

Esos terrenos eran incluidos en su consideración del problema no como los territorios "de" los indios misioneros, sino dentro de esa extensa porción de tierra de "la Campaña" que era necesario "arreglar".

De todos modos, la imprecisión del autor no debería sorprender porque durante la época colonial lo que caracterizaba la ocupación del espacio era su fragmentación. Tal como fue apuntado por Frega para la banda norte del Río de la Plata, y puede ser extendido para otras zonas del virreinato, “Las zonas ocupadas coincidían con las ciudades que enlazaban las rutas comerciales, las regiones de

Félix de la Roza siendo Administrador de ella", 1804. En Correspondencia y expedientes de la Administración de Correos de Buenos Aires (1804-1807). Archivo General de Indias (AGI), Correos, 16 ${ }^{\mathrm{a}}$. Agradezco a Ana Frega haberme facilitado la reproducción de este mapa. Fue editado por J osé TORRE REVELLO, "Mapa de las estafetas y postas de la parte septentrional del Río de la Plata establecidas por don J osé de la Roza (1804)", Ministerio de Educación y Cultura, UBA, Facultad de Filosofía y Letras, Instituto de Geografía, Serie B, № 4 de Documentos cartográficos, planimétricos e iconográficos, Buenos Aires, 1952.

33 ISLAS, Ariadna, “En búsqueda de fronteras perdidas...”, ob. cit., p. 8; e ISLAS, Ariadna, “Límites para un Estado, ob. cit., p. 180.

34"Noticias...", f. 16v. 
producción de «frutos del país» o los fortines. El resto era dominio de los «indios infieles», o de malhechores, o simplemente se hallaba deshabitado"35.

Además, la demarcación de límites claros, tan cara a la historiografía nacionalista, no habría sido constitutiva de las unidades políticas de Antiguo Régimen, como sí lo sería luego para los Estados Nacionales modernos. Fue el historiador brasileño J oão Paulo Pimenta quien puso atención en el equívoco que llevó a la historiografía tradicional a confundir los territorios coloniales con los territorios nacionales que emergieron de su desarticulación. Porque, a diferencia de lo que ocurrió con estos últimos, cuyos territorios fueron mayormente continuos en términos geográficos, los imperios ibéricos habían constituido unidades políticas a partir de áreas que se encontraban dispersas por diversos continentes. E incluso, esos imperios aspiraban a ejercer jurisdicción sobre espacios poco conocidos y mal definidos, como muestra claramente el discurso del Anónimo. La lógica seguida en la conformación de esos imperios discontinuos, propia de Antiguo Régimen, consideraba los diversos territorios como patrimonio particular del rey, por lo que adquirían unidad y sentido en su vinculación con la monarquía que daba cohesión al conjunto. En los estados nacionales modernos, en cambio, sí fue necesario definir claramente el territorio porque era el espacio de jurisdicción de la soberanía de ese Estado en relación a sus vecinos y a la comunidad internacional ${ }^{36}$.

Pimenta advirtió que resulta poco conveniente en términos analíticos "atribuirles a los sujetos de la época una idea de territorio que entonces no existía y que fue definida en construcciones ideológicas posteriores"37. Por lo tanto, para no pecar de anacronismo, los documentos producidos por funcionarios de las monarquías ibéricas deben ser analizados teniendo en cuenta ese carácter de discontinuidad que los caracterizaba. Porque además, ello permite explicar mejor esa falta de precisión con que los funcionarios se referían a algunos espacios sobre los que supuestamente ejercían dominio.

\footnotetext{
35 FREGA, Ana, “La constitución de la Banda Oriental como provincia...”, ob. cit., p. 51.

36 PIMENTA, J oão Paulo, Estado y nación hacia el final de los imperios ibéricos: Río de la Plata y Brasil, 1808-1828, Buenos Aires, Sudamericana, 2011, pp. 57-58.

${ }^{37}$ Ibidem, pp. 59-60.
} 
La misma imprecisión con que el autor de las Noticias abordaba la cuestión de la delimitación territorial se vio reflejada en los diversos tratados que firmaron las coronas de España y Portugal en la segunda mitad del siglo XVIII. Con el cometido de solucionar los conflictos de límites que las enfrentaba en la América Meridional, hacia 1790, cuando escribió el autor del Anónimo, habían firmado el tratado de Madrid en 1750, el de El Pardo en 1761 y el de San Ildefonso en 1777, y en los tres casos los límites se habían visto modificados. Los tratados fueron el resultado de la vía diplomática en la tramitación de esos conflictos, pero también se hizo uso de la vía militar para imponer situaciones de hecho a la otra parte en litigio. Los límites de las posesiones de una y otra corona estaban en un proceso de constante redefinición. De hecho, tal como fue apuntado por Islas, "Podría pensarse la región al oriente del Paraná como una zona frontera en su conjunto, en cuanto puede ejemplificarse su uso como objeto de transacción en diversos tratados"38.

A partir del tratado de Madrid de 1750 se introdujeron cambios en la forma de tramitar diplomáticamente las disputas sobre límites. Como ha estudiado muy bien la historiografía, ello significó abandonar la apelación a la concesión papal y al Tratado de Tordesillas como fuente de legitimidad para la posesión de los territorios americanos. ${ }^{39} \mathrm{~A}$ partir de ese momento, la discusión limítrofe se realizó de acuerdo al principio de uti possidetis, que implicaba reconocer como elemento de legitimidad la ocupación efectiva de los territorios ${ }^{40}$. Y se estableció que para la

\footnotetext{
38 ISLAS, Ariadna, “En búsqueda de fronteras perdidas...”, ob. cit., p. 7.

39 Para una mirada actualizada y despojada de los presupuestos nacionalistas ver: ISLAS, Ariadna, "En búsqueda de fronteras perdidas...", ob. cit. y TEJERINA, Marcela, "La lucha entre España y Portugal por la ocupación del espacio: una valoración alternativa del Tratado de San Ildefonso de 1777", Revista de Historia, Revista de Historia, Departamento de História da Faculdade de Filosofia, Letras e Ciências Humanas, USP, 1996, № 135, pp. 31-40.

40 El carácter inaugural de Tratado de 1750 quedó expresado en el artículo 1o donde se postulaba: "quedará abolido cualquier derecho y acción que puedan alegar las dos Coronas, con motivo de la bula del Papa Alejandro VI, de feliz memoria, y de los tratados de Tordesillas, de Lisboa y Utrecht, de la escritura de venta otorgada en Zaragoza, y de otros cualesquiera tratados, convenciones y promesas". Texto del tratado disponible en: http:// www.cervantesvirtual.com/obra-visor/tratadofirmado-en-madrid-a-13-de-enero-de-1750-para-determinar-los-limites-de-los-estadospertenecientes-a-las-coronas- de espana-y-portugal-en-asia-y-america--0/html/ff8d40ae-82b111df-acc7-002185ce6064_2.html
} 
demarcación de la "raya" que separaría a los dominios de ambas coronas se echaría mano de los accidentes geográficos ${ }^{41}$.

Esos cambios no siempre fueron bien recibidos ni por los vasallos que habitaban los territorios en disputa, ni por los funcionarios que siguieron echando mano de la concesión papal y del tratado de Tordesillas como principios de legitimidad ${ }^{42}$. El autor del Anónimo, por su parte, era bastante crítico respecto de la tramitación política y diplomática que se había seguido con el imperio portugués. Desde la fundación de Colonia del Sacramento en 1680 y hasta 1794 en que escribía, la política de poblamiento de la corona española reactiva ante los avances portugueses había logrado muy magros resultados. Y las concesiones realizadas por la vía diplomática habían significado el descuido de unos territorios que, por sus potencialidades productivas, podían colaborar en quitar a España de su atraso relativo:

\begin{abstract}
“Desde esta fecha podemos asegurar á V.E. que se halla pensionada la nación Española, á estar con las armas en las manos contra sus Amigos y Vecinos los Portugueses, sin que los enlazes por sangre de estas dos coronas hayan logrado poner la Paz entre ellas. Ciento y catorce años de guerra (mas ó menos declarada) pero siempre perjudicial á la España, contamos hasta hoy desde aquella Época, sin haver adelantado otra cosa que reforzar á nuestro contrario por medio de vnas cesiones, mui considerables que ha sabido negociar en los apuntes y tratados aque repetidas veces hemos venido, huyendo de vn rompimiento: y quando vno solo havria sido suficiente á reconquistar nuestras posesiones usurpadas por aquellos, y á descartarnos de vn vecino, mui antiguo y mui interesado de estarnos incomodando hemos estado sobrellevando el espacio de 114 años para que la larga posesión en que los ha tolerado el sufrimiento los haya hecho entrar en presunsion de Senores"43.
\end{abstract}

El tratado de San Ildefonso había establecido la necesidad de dejar sin ocupar unos territorios "neutrales" a fin de que los comisarios pudieran establecer

\footnotetext{
${ }^{41}$ FREGA, Ana, "Las fronteras de la soberanía...", ob. cit., p. 223.

42 En el caso de los pueblos guaraníes ese descontento llegó a alcanzar el nivel de resistencia armada. La permuta de los territorios misioneros por el de Colonia del Sacramento establecida por el tratado de Madrid del 13 de enero de 1750 fue resistida por las armas en lo que se conoció como la guerra guaranítica (1754-1756).

43 “Noticias...”, f. 8v.
}

Facultad de Humanidades y Ciencias de la Educación, Universidad de la República

- 51 - 
la demarcación. ${ }^{44}$ Pero, dada la demora de las partidas demarcadoras las dificultades fronterizas se habían visto agravadas:

"no haviendose podido fijar esta línea todavia, después de 10 años q.e están trabajando en su arreglo tres partidas de Comisarios Españoles, á el cargo de otros tantos oficiales de Marina de acuerdo con los Comisarios Portugueses diputados á el mismo fin por su corona, no podemos contar $\mathrm{p}^{\mathrm{r}}$ ahora con otro limite cierto q. ${ }^{\mathrm{e}}$ con el delos terrenos neutrales delas dos Coronas; y con este motivo son mas frequentes los robos y los contrabandos y debe andar mas solicita la atención del que govierna”45.

El problema de la frontera externa con Portugal es uno de los aspectos centrales en la presentación del territorio que se realizó en las Noticias. Sin embargo, aunque por razones de espacio aquí no se analizan, el autor entendía que para la solución de ese problema era necesario quebrar también las fronteras internas: ocupar el espacio mediante políticas de poblamiento y civilizar o españolizar a los malentretenidos o changadores que, en alianza con los portugueses, perjudicaban los intereses de la corona.

Por otra parte, en el repaso de las objeciones que es posible realizar a la interpretación nacionalista de la conciencia geográfica del autor del Anónimo de 1794, debería reconocerse que en la misma época en que se escribieron las Noticias hubo pedidos de los vecinos de Montevideo para aumentar la jurisdicción de la ciudad sobre la campaña, que fueron muy bien estudiados por la historiografía tradicional ${ }^{46}$. Pero también es cierto que en el momento en que esos pedidos fueron

\footnotetext{
44 Por el artículo 6 del tratado de San Ildefonso del 11 de octubre de 1777 se había definido las tierras neutrales entre los dominios de ambas coronas: "en el cual no puedan edificarse poblaciones por ninguna de las dos partes, ni construirse fortalezas, guardias, o puestos de tropas: de modo que los tales espacios sean neutrales, poniéndose mojones y señales seguras, que hagan constar a los vasallos de cada nación el sitio de donde no deberán pasar." http:// www.cervantesvirtual.com/obra-visor/tratado-preliminar-sobre-los-limites-de-losestados-pertenecientes-a-las-coronas-de-espana-y-portugal-en-la-america-meridional-ajustado-yconcluido-en-san-lorenzo-a-11-de-octubre-de-1777--0/html/ff8d38fc-82b1-11df-acc7$002185 \mathrm{ce} 6064$ 1.html

45 “Noticias...", ob. cit., f. 13.

46 Ver por ejemplo: PIVEL DEVOTO, J uan E., ob. cit., pp. 131-151. Allí el autor repasa los pedidos de ampliación de la jurisdicción de 1738, 1769, 1785 y 1795 realizados por el cabildo o por funcionarios de la corona en Montevideo.
} 
elevados a la corona, no eran más que una de las voces que clamaban en la disputa por los recursos.

Sin embargo, el autor del Anónimo no prefiguraba la unidad política y administrativa del territorio de "la Campaña" y no compartía el espíritu que llevó a realizar esos pedidos de ampliación de la jurisdicción de Montevideo. Un claro ejemplo de ello fueron las propuestas concretas que realizó para mejorar la evangelización de ese territorio. El autor del Anónimo creía que uno de los grandes problemas que enfrentaba la corona en "la Campaña" era su falta de evangelización. El autor lo explicaba como una consecuencia de las grandes distancias que debían recorrerse desde Buenos Aires para arribar a algunas de las regiones que era preciso cristianizar, y también de los altos costos que era necesario enfrentar para hacerlo. Para subsanar esa falta de prelados y las dificultades que estos tenían para recorrer sus parroquias anualmente, el autor propuso la creación de un obispado en Montevideo y la posibilidad de dividir las jurisdicciones eclesiásticas sobre ese territorio:

"si fuese del agrado de S.M. erigir vna Cathedral en Montevideo hay el arbitrio de partir del Norte á Sur el territorio de la campaña, y poner á cargo del obispo de Montevideo el terreno oriental hasta el mar, y el occidental á el de B.s Ayres, dividiendo en los mismos términos los fueros de ambas Diócesis. Porq. e todo el Campo que corre desde la ciudad de corrientes hasta la colonia del Sacramento, entre el Paraná y el Rio Negro esta mas cerca de B.s Ayres que de Montevideo y seria mas facil asistirse y visitarse por aquel Prelado que por este y assi se lograria que sin quitar renta á aquella mitra quedase la suficiente para vn obispo y doce Prebendados en Montevideo ${ }^{47}$ ".

Como puede verse, a la hora de definir cuál era la mejor manera de gestionar el espacio, el autor entendió que al territorio comprendido entre el río Paraná y el río Negro se accedía más fácil desde Buenos Aires, mientras que a los territorios al sur de este último río se accedía mejor desde Montevideo, por lo que allí radicaba la conveniencia de realizar la reforma propuesta.

47 “Noticias...”, ob. cit., ff. 71v-72. 
El autor sugería cambios en la administración de los diezmos de "la Campaña", que en esa época ya se realizaba desde dos cabeceras distintas: Buenos Aires y Montevideo48. Es verdad que su propuesta evitaba perjudicar al obispado de Buenos Aires con la pérdida de toda la masa decimal, y que en ese sentido la idea de partir el territorio de norte a sur puede verse como contemporizadora con los intereses bonaerenses. Sin embargo, las razones aducidas por el autor eran razones de peso. Para la época en que él escribía, tal como fue apuntado por Frega, “El nivel de desarrollo de los medios de comunicación y transporte no puede soslayarse [...] Allí debemos buscar lo que está «cerca» y lo que está «lejos», y no en las distancias matemáticas o geográficas"49. En ese sentido, y dada la tecnología disponible, los diversos cursos de agua -fundamentales para la explotación ganadera-, podían ser un obstáculo para las comunicaciones y para la gestión de ese espacio por parte del gobierno, que era lo que preocupaba al autor del Anónimo.

Que posteriormente las aspiraciones territoriales de los vecinos de Montevideo coincidieran en mayor o menor grado con la Provincia Oriental ${ }^{50}$, y luego con el Estado Oriental, no permite realizar la imputación retrospectiva que la historiografía nacionalista realizó. Menos aun en el caso de este testimonio que es el producto intelectual de un funcionario español cuya forma de razonar es claramente a escala imperial. Esto quiere decir, para la época, pensar una determinada región del imperio en relación a los vínculos existentes y futuros con su metrópoli, y a través de ésta con el resto del imperio.

\section{Territorio e identidad en el Anónimo de 1794}

Cuando el autor del Anónimo imaginaba el Río de la Plata y las potencialidades económicas del territorio lo hacía en relación a su metrópoli, e

\footnotetext{
48 MORAES, María Inés, ob. cit., pp. 90-107.

49 FREGA, Ana, “La constitución de la Banda Oriental como provincia...”, ob. cit., p. 49.

50 Tal como fue señalado por Islas, la denominación "Provincia Oriental" se refirió a espacios territoriales que fueron modificándose a lo largo del proceso de independencia de acuerdo al desempeño militar de los bandos enfrentados. ISLAS, Ariadna, "Límites para un Estado...", ob. cit., p. 176 y ss.
} 
incluso muchas veces sus análisis y propuestas los realizaba pensando en el beneficio de España. En ese sentido, el autor sería un caso típico de funcionario borbónico identificado con el bien común de la monarquía y no con los intereses locales del territorio en el cual desempeñaba sus funciones. Sin embargo, a la hora de representarse el territorio del virreinato como parte del imperio, lo valoraba de un modo tal que ello podría estar denotando de parte del autor ciertos niveles de identificación con ese "Reino".

El autor del Anónimo sería un caso típico de superposición y coexistencia de las diversas identidades que estaban en juego dentro de la monarquía católica. Igualmente, de los diversos niveles identitarios descriptos por Guerra51, el que parecería primar en este caso sería el que estaba asociado a la nación católica, de la cual además se desprendería en un segundo plano su patriotismo en defensa de la monarquía. Ello queda demostrado cuando afirmó que entre los motivos que lo llevaron a escribir su obra primaron más el ser católico que el ser patriótico:

“Es tan inherente esta compasion á todo Catholico á el ver el estado del campo; y el carácter de aquellos habitadores, que si hemos de hablar con verdad, ella ha sido la causa motiva de nuestra determinacion a tomar la pluma sobre el asunto de este papel, tan desigual a nuestras fuerzas. Conocemos ser indisputable el beneficio que resultara, á el Estado, á la Iglesia, á la real Hacienda y a todas las órdenes de la Nacion, de que se plantifique la reforma de la campaña, pero preciando antes de Catholicos que patrióticos, confesamos que el bien espiritual de tantas Almas, es lo que mas nos ha inducido á escribir, rompiendo por medio de todas nuestras desconfianzas: y si con efecto fueren parte nuestras tareas de que se verifique la conquista de aquella tierra, nos lisongearemos de haver hecho vn servicio á ambas Magestades" 52 .

A favor de la preeminencia de la identidad católica por encima de las demás identidades que fueron puestas en juego en el discurso del autor del Anónimo

51 Esas identidades iban desde el nivel local vinculado al lugar de nacimiento y/ o residencia - "pueblos villas y ciudades"-; pasaban por niveles intermedios como podían ser los reinos y provincias, hasta llegar al nivel más agregado que era el de la nación española encarnada en la propia monarquía, que era en los hechos la que daba cohesión a ese mosaico de comunidades políticas. GUERRA, François-Xavier, "Las mutaciones de la identidad en la América hispánica", Antonio ANNINO, François-Xavier GUERRA (coords.), Inventando la nación: Iberoamérica siglo XIX, México, Fondo de Cultura Económica, 2003, pp. 190 y ss.

52 “Noticias...", ob. cit., f. 72v. 
podría argüirse, también, el hecho de que éste se hubiera autoidentificado como un político cristiano antes que como funcionario:

“Nosotros aspiramos y principalmente a la extinción de vandidos y forajidos que inundan aquellos campos; ala civilización política y moral de sus habitantes; a la propagación legal dela especie humana; y ala extincion del contrabando. Estos son los objetos que nos hemos propuesto en la curación de aquella Babilonia: objetos dignos de un político christiano y que asu sombra nos han de nacer los frutos temporales que necesitamos, porque seguramente sabemos que despues que los labradores de este gremio sean personas conocidas y morigeradas no vagara por inciertas manos el dominio dela Campaña; se tributará á la Corona; se acreditara con obras la Religión, juntaran á la cria del ganado la cultura dela tierra, se dedicaran á algún ramo de industria; no acojeran fugitivos; darán consumo a las manifacturas de España y tropas á nuestro Exercito"53.

Lo anterior muestra que para el autor existía una interdependencia entre la cristianización -como sinónimo de "civilización"- y la configuración de vasallos útiles para la monarquía. De hecho, las propuestas que realizó para el reordenamiento de la campaña se fundamentaban en que daba por descontada esa interdependencia.

Por otra parte, el autor no dubitaba a la hora de posicionarse sobre la necesidad de subordinar los intereses de la colonia en relación a su metrópoli. Muchas de las propuestas que realizó para el mejoramiento del Río de la Plata en general y de la Banda Norte en particular, las hizo en beneficio de la península y para restituir ese vínculo de dependencia que él entendía se hallaba puesto en entredicho:

'Y lo mas apreciable de todo es que se logra sacarle á la America todo su sobrante y amortizarlo en España en plata física, sin que la nación este gastando de su fondo atesorado ni dependa la Metropoli de sus colonias, como esta sucediendo, no sin peligro inmediato de que la Señora de las Provincias llegue á ser tributaria de la que debe ser su basalla”54.

\footnotetext{
53Ibíd., ff. 53-53v.

54Ibíd., f. 59v.
} 
A pesar de esta fuerte identificación con los intereses de la monarquía que puede verse in extenso a lo largo de la obra, el autor abrió su discurso alabando el territorio del Río de la Plata y exaltando sus virtudes en relación a otros lugares del mundo. Ello ocurrió, por ejemplo, cuando estimó la dimensión del territorio que debería gobernar el nuevo virrey, al que dedicaba su obra. Según el autor, el virreinato aventajaba a otros imperios conocidos que eran de grandes dimensiones:comprendía "vn territorio tan dilatado que dexa atrás en extensión el Ymperio de los Tartaros, y el de los Chinos en el Asia"55.

Al mencionar a la Banda Norte del Río de la Plata, el autor anunciaba al virrey que tenía "a un lado de este territorio vna Provincia tan amena dilatada y poderosa que basta bien quidada a dar Renta a dos Principes coronados"56. Las amplias potencialidades productivas de esos territorios -o su "amenidad"-, sumadas a su extensión permitían augurar que se obtendría de ellos un muy buen provecho económico. Advertía también que “Vá V.E. á encargarse del mando de vna nueva región, civilizada y católica en mucha parte; pero silvestre y feroz en otra"57; por lo cual había mucho por hacer en materia de políticas y de buena administración.

El autor del Anónimo le aseguraba al virrey que en el futuro “V. E. se habrá de gloriar de ser el Gefe, el Caudillo, el Padre y el Super Intendente de este tesoro y de estos Vasallos"58. Sin embargo, este anuncio era un proyecto, porque para ello era necesario realizar una serie de políticas que el autor del Anónimo sintetizaba muy bien en este fragmento inicial de la obra:

'V.E. tendrá el placer mas inocente quando por su vigilancia y felices pensamientos, consiga establecer la agricultura en aquel campo, afianzar la cria de ganado vacuno, mejorar el

\footnotetext{
55 Ibíd., f.1.

56 Ibíd., f.4.

57 Ibíd., f. 1.

58 Ibíd., f. 4v.
} 
comercio de cueros, desterrar la ociosidad, perseguir los facinerosos, introducir la Politica, frontificar las fronteras, levantar Pueblos, formar Regimientos, y plantar la Religion”59.

La sobrevaloración que el autor realizó del virreinato en relación al resto del mundo fue por cierto considerable, ya que llegó a afirmar que se trataba de "la mas opulenta y mas amplia Provincia de todo el orbe"60. E, incluso, igualó la "América Meridional" al paraíso terrenal, y apoyó su argumento en las descripciones que diversos viajeros habían realizado en relación al "Viejo Mundo". A las ventajas naturales con que Dios había agraciado a esos territorios, el autor opuso los desórdenes con que se había gestionado el espacio:

\begin{abstract}
"Mas de una vez hemos oído decir á los hombres de juicio hartos de correr toda la Europa, que solo el parayso terrenal excederia en hermosura y fecundidad la tierra meridional de nuestra America: y descriviendola en un bosquejo, dicen que son un espacio sin medida de valles amenísimos, intercalados de elevaciones agradables, que despidiendo las aguas á el llano, forman un numero sin cuento de arroyos, lagunas y Rios caudalosos que corren á todos vientos, los quales quebrando, y visitando la tierra en sus entrañas la fecundan con sus juegos haciéndola producir robustos pastos, aromas yervas, flores y medicinales, que al paso que recrean la vista y el olfato combida á el hombre á el trabajo dela agricultura con seguridad deque no seria burlada su fatiga. Pero hablandonos estos mismos practicos delos desordenes dela Campaña, no encuentran las palabras que han de espresar su concepto. Saben explicarnos los portentos de la naturaleza y no saben definir la injusticia de los hombres sobre un lugar de creacion, donde todos sus objetos deven levantarle el corazón azia el Hacedor de todos ellos"61.
\end{abstract}

La alta consideración que tenía de esos territorios en cuanto a la riqueza que podía extraerse de ellos se basaba en que los conocía directamente, ya que el autor entendía que para poder apreciarlos en su justa medida era necesario conocerlos de primera mano:

59 Ibíd., f. 4v.

60 Ibíd., f. 4.

${ }^{61}$ Ibíd., ff. 19v-20. 
"verificándose entonces lo que hemos concebido muchas veces y oydo repetir á diferentes personas que no se puede creer, ni hacer juicio adequado de la riqueza de aquellos campos sin pasar á verlo, porque nunca se computa bien su valor por mucho que se diga”62.

Algunas de las valoraciones que el Anónimo realizó sobre el territorio del Río de la Plata en general y de la Banda Norte en particular plantean la pregunta acerca del nivel de identificación con esos territorios y cómo esto se articulaba con su rol de funcionario del imperio. Máxime cuando hacía solo ocho años que se encontraba en el Río de la Plata, proveniente probablemente de la península, y ya parecía haber desarrollado una valoración considerable por esa nueva tierra, a la que definía como un "tesoro", o como una provincia "amena dilatada y poderosa" y la "más opulenta" del orbe.

Para entender la amplitud del discurso patriótico presente en el Anónimo es necesario cotejarlo con los estudios sobre las mutaciones del patriotismo hispánico a mediados del siglo XVIII, que han mostrado cómo los Borbones buscaron articular una percepción abstracta de la patria como proyecto político de la monarquía, dotando al concepto de un sentido nuevo respecto al tradicional, que lo relacionaba estrictamente al lugar de nacimiento. A partir de allí, el patriotismo se asoció a la prosperidad económica y al florecimiento de las artes útiles dentro del imperio como un todo y se identificó al patriota como aquel que coadyuvaba a la utilidad pública de la Nación 63 .

Como fue visto, pese a ser uno de los funcionarios borbónicos fuertemente convencido de que el bello reino que describía era una colonia de España, el autor no dejaba por ello de considerar ese territorio "un centro del mundo"64. A diferencia de lo que el historiador Jorge Cañizares-Esguerra encontró en los

\footnotetext{
62 Ibíd., f. 68.

63 LOMNÉ, Georges (ed.), Patria, Tomo 8 de Javier FERNÁNDEZ SEBASTIÁN (dir.), Diccionario político y social del mundo iberoamericano. Conceptos políticos fundamentales, 1770-1870, [Iberconceptos-II], Madrid, Universidad del País Vasco/Centro de Estudios Políticos y Constitucionales, 2014, p.21y ss.

64 CAÑIZARES-ESGUERRA, J orge, “La ilustración hispanoamericana: una caracterización”, J aime RODRÍGUEZ (coord.), Revolución, independencia y las Nuevas Naciones, Mapfre, 2005, p. 94.
} 
discursos patrióticos novohispanos ${ }^{65}$, el discurso del Anónimo sobre el Río de la Plata no habría sido una reacción localista a las políticas centralizadoras metropolitanas, sino un resultado natural de esas políticas centralizadoras.De hecho, el caso del Anónimo abogaría en favor de la idea planteada por el historiador Gabriel Entin respecto a que, en términos analíticos, el patriotismo americano no debería ceñirse al patriotismo criollo, puesto que en el proceso de configuración de identidades regionales de fines del siglo XVIII parecería haberse dado una imbricación en la participación de criollos y españoles, que aún no ha sido desentrañada de manera suficiente por la historiografía. ${ }^{66}$

En este trabajo se cree que el autor de las Noticias, mediante la elaboración de una "geografía patriótica"67 o una "fisiografía apasionada"68 del territorio rioplatense, participó de ese proceso de configuración de identidades regionales que se estaba tramitando en el imperio español. Y que en ese sentido, podría incluirse entre los funcionarios que vehiculizaron el trayecto entre ciencia y conciencia descripto por el historiador J osé Portillo Valdés para otras latitudes del imperio 69 .

65 CAÑIZARES-ESGUERRA, J orge, Cómo escribir la historia del nuevo mundo: historiografías, epistemologías e identidades en el nuevo mundo del Atlántico del siglo XVIII, México, FCE, 2007, pp. 30, 448 y 488-489. Este autor plantea que los estudios tradicionales de la ilustración hispanoamericana, al poner el énfasis en el rastreo de las ideas europeas en los escritos americanos, dejaron a un lado el estudio de lo que mejor define ese proceso, que es el fenómeno del patriotismo criollo. En ese sentido, propone prestar atención a los debates de científicos y de anticuarios del siglo XVIII como característicos del tipo de esfera pública que se configuró en Hispanoamérica. Un enfoque parecido al de este autor se sigue en: ACHIM, Miruna, "Debates Ilustrados y Participación Política en el México del Siglo XVIII", Revista 20/10 Historia,2012,Vol. 1, disponible en: http://www.20-10historia.com/articulo8.phtml.

66 ENTIN, Gabriel, "El patriotismo americano en el siglo XVIII. Ambigüedades de un discurso político hispánico", Veronique HÉBRARD y Geneviève VERDO (comps.), Las independencias hispanoamericanas: un objeto de historia, Madrid, Casa de Velázquez, 2013, pp. 19-20.

${ }^{67}$ GUERRA, François-Xavier, “Las mutaciones de la identidad...” ob. cit., p. 200.

68 PORTILLO VALDÉS, J osé María, Crisis atlántica: autonomía e independencia en la crisis de la monarquía hispana, Madrid, Fundación Carolina-Marcial Pons, 2006, p. 50.

69 Portillo Valdés refiere, entre otros, al caso de la Expedición Botánica de Celestino Mutis de 1783 en Nueva Granada y la influencia que ésta tuvo en la formación de la generación de la que formaron parte J oaquín Gutiérrez o Camilo Torres, cuyos papeles en la configuración de una identidad local neogranadina fueron bien importantes, sobre todo en el contexto revolucionario. Refiere también como otro ejemplo de este mismo trayecto entre ciencia y conciencia a Victorián de Villava (fiscal de la Audiencia de Charcas entre 1791 y 1802), y la influencia que este funcionario tuvo en el Río de la Plata, específicamente en la generación de criollos que protagonizarían los sucesos revolucionarios. Ibíd., p. 50. 
De hecho, en el caso del Río de la Plata, durante la discusión pública que se tramitó en torno al "arreglo de los campos" se puso en circulación una serie de discursos de economía política que en otras partes del imperio y en la propia península fueron producidos y difundidos a través de las Sociedades Económicas de Amigos del País y de las Sociedades Patrióticas. Un tipo de institución que en el Río de la Plata no pasó del proyecto ${ }^{70}$, pero cuyas funciones se cumplieron entonces por otros canales, entre los cuales la prensa también jugó un papel fundamental aunque posterior ${ }^{71}$.

Aunque este es un tema que requiere ser investigado, a manera de hipótesis se propone que el Anónimo y los demás informes para "el arreglo de los campos" pusieron a disposición una serie de conocimientos "útiles" sobre el espacio geográfico del Río de la Plata y sus potencialidades, y plantearon la necesidad de implementar una serie de políticas para su mejor posicionamiento dentro del imperio, que fueron muy importantes para el proceso de conformación de una identidad local. En ese sentido, no debería sorprender que para la elaboración de la identidad oriental que comenzó a gestarse a partir de 1811, al calor del propio proceso revolucionario, se haya echado mano de esa información disponible. Lo que explicaría que las ideas que se propusieron para ese "arreglo" hayan sido usadas posteriormente en un contexto político distinto al que habían sido producidas, ya que su origen se explicaba en clave imperial mientras que esos otros usos fueron realizados en el contexto de desgajamiento del imperio y muchas veces en ruptura con la metrópoli 72 .

\footnotetext{
70 En oportunidad de actuar como censor del Telégrafo Mercantil, Rural, Político, Económico e Historiográfico del Río de la Plata, periódico editado en Buenos Aires, Mata Linares además de recomendar su publicación, encomendó a su editor, Francisco Antonio Cabello y Mesa, promover la constitución de una sociedad patriótica que no llegó concretarse. FURLONG, Guillermo, Historia y bibliografía de las primeras imprentas rioplatenses 1700-1850. Tomo II: La imprenta en Buenos Aires, 1785-1807, Buenos Aires, Librería del Plata, 1955, p. 236. TORRE REVELLO, J osé, El libro, la imprenta, y el periodismo durante la dominación española, Buenos Aires, Instituto de Investigaciones Históricas de la Facultad de Filosofía y Letras de la Universidad de Buenos Aires, 1940, pp. 188-189.

${ }^{71} \mathrm{El}$ primer periódico rioplatense fue elTelégrafo Mercantil, Rural, Político e Historiógrafo del Río de la Plata,que salió entre 1801 y 1802, y elSemanario de Agricultura, Industria y Comercio que le siguió, salió entre 1802 y 1807.

72 Un ejemplo de ese proceso de apropiación y reinvención en clave de patriotismo revolucionario de los conocimientos que el Anónimo y los otros escritos producidos para "el arreglo de los campos"
} 


\section{Colofón}

Puede decirse que el autor del Anónimo al realizar sus propuestas de "arreglo" para los "campos de Buenos Aires y Montevideo" no refirió propiamente a la Banda Oriental, porque en esa época no se pensaba el territorio como una unidad administrativa sino bajo varias jurisdicciones. E incluso, como se vio, el autor consideraba que algunos de los territorios que según la historiografía nacionalista conformaban esa Banda Oriental "natural", era más conveniente que se administraran desde Buenos Aires, en razón de la mejor comunicación con la capital del virreinato. Tampoco se refirió a la Provincia Oriental, porque esa definición política se desarrolló a lo largo del proceso de independencia, y como consecuencia de ese mismo proceso. El autor se refirió a un espacio político y económico que en la época se encontraba en disputa y cuyos límites los protagonistas no podían dar con certeza, como consecuencia, en parte, de esa misma disputa. Sobre esos territorios se configuró a partir del proceso revolucionario un Estado nación, pero esa sería otra historia.

Para este funcionario en particular, parecería que el hecho de que el virreinato pudiera ser visto como uno de los lugares mejor dotados del globo no era incompatible con su condición subordinada a la metrópoli. En ese sentido, su exaltación de las potencialidades productivas del Río de la Plata adquiere sentido si es leída desde su fuerte patriotismo hispánico.

pusieron a disposición puede ser el "Reglamento Provisorio de la Provincia Oriental para el fomento de su Campaña y Seguridad de sus hacendados" del año 1815. Para el estudio de la configuración de la identidad oriental en el contexto revolucionario ver los trabajos de Frega y su equipo ya citados, y PIMENTA, J oão Paulo, "Província Oriental, Cisplatina, Uruguai: elementos para uma história da identidade oriental (1808-1828)", Marco PAMPLONA y María Elisa MÄDER (orgs.), Revoluçõesde independências e nacionalismo nas Américas: Região do Prata e Chile, San Pablo, Paz e Terra, 2007; y PIMENTA, J oão Paulo, “¿A quién debería pertenecerle la banda oriental? Elementos para comprender la Independencia de Brasil a partir del Río de la Plata”, Nuevo Mundo Mundos Nuevos, Debates 2013, consultado el 28 abril 2015.

Disponible en: http:// nuevomundo.revues.org/65338;DOI:10.4000/ nuevomundo.65338. 


\section{Bibliografía}

BARRÁN, J osé Pedro y Benjamín NAHUM, Bases económicas de la Revolución artiguista, Montevideo, Ediciones de la Banda Oriental, 1964.

BRITO STÍFANO, Rogelio, Edición y estudio introductorio a "Noticias anónimas sobre el estado de los campos de la Banda Oriental al finalizar el siglo XVIII", Revista Histórica del Museo Histórico Nacional, 1953, Nos 52-54, pp. 301-516.

CAMPAL, Esteban, Hombres, tierras y ganados, Montevideo, Talleres Gráficos, 1962.

Azara y su legado al Uruguay. Montevideo, Ediciones de la Banda Oriental, 1969.

CAÑIZARES-ESGUERRA, J orge, "La ilustración hispanoamericana: una caracterización", J aime RODRÍGUEZ (coord.), Revolución, independencia y las Nuevas Naciones, Mapfre, 2005, pp. 85-97.

CONTRERAS, Remedios y Carmen CORTÉS, Catálogo de la Colección Mata Linares, 5.vols., Madrid, Real Academia de la Historia, 1970-1977.

ENSINCK, Oscar Luis, "La historia argentina y los archivos españoles", Quinto Centenario, Universidad Complutense de Madrid, 1987, Vol. 12, pp. 163-166.

ENTIN, Gabriel, "El patriotismo americano en el siglo XVIII. Ambigüedades de un discurso político hispánico", Veronique HEBRARD y Geneviève VERDO (comps.), Las independencias hispanoamericanas: un objeto de historia, Madrid, Casa de Velázquez, 2013, pp. 19-34.

FISHER, J ohn, El Perú Borbónico 1750-1824, Lima, IEP, 2000.

FREGA, Ana (coord.), Historia regional e independencia del Uruguay. Proceso histórico y análisis crítico de sus relatos. Montevideo, Ediciones de la Banda Oriental, 2009.

FREGA, Ana, "La constitución de la Banda Oriental como provincia. Apuntes para su estudio desde un enfoque local", Historia y Docencia, APHU, 1994, № 1, pp. 47-56.

"Las fronteras de la soberanía. Apuntes para un atlas de la banda oriental del río Uruguay en la primera mitad del siglo XIX", J avier FERNÁNDEZ SEBASTIÁN y Cecilia SUÁREZ CABAL (eds.), La subversión del orden por la palabra. Tiempo, espacio e identidad en la crisis del mundo ibérico. Siglos XVIII-XIX, Bilbao, Servicio Editorial de la UPV, 2015, pp. 219-239. 
Pueblos y soberanía en la revolución artiguista. La región de Santo Domingo Soriano desde fines de la colonia a la ocupación portuguesa. Montevideo, Ediciones dela Banda Oriental, 2007.

“Uruguayos y orientales: itinerario de una síntesis compleja”, J osé Carlos CHIARAMONTE, Carlos MARICHAL y Aymer GRANADOS (comps.), Crear la nación. Los nombres de los países de América Latina, Editorial Sudamericana, 2008, pp. 95-112.

GUERRA, François-Xavier, "Las mutaciones de la identidad en la América hispánica", Antonio ANNINO, François-Xavier GUERRA (coords.) Inventando la nación: Iberoamérica siglo XIX, México, Fondo de Cultura Económica, 2003, pp. 185-220.

ISLAS, Ariadna, "En búsqueda de fronteras perdidas. Algunas notas sobre la construcción política de las "fronteras naturales" en la región platense sobre la lectura de viejos mapas (1600 ca.- 1853)", s/d.

"Límites para un Estado. Notas controversiales sobre las lecturas nacionalistas de la Convención Preliminar de Paz de 1828", Ana FREGA (coord.), Historia regional e independencia del Uruguay. Proceso histórico y análisis crítico de sus relatos. Montevideo, Ediciones de la Banda Oriental, 2009, pp. 169-216.

MARILUZ URQUIJ O, J osé, "Las memorias de los Regentes de la Real Audiencia de Buenos Aires Manuel Antonio de Arredondo y Benito de la Mata Linares", Apartado de la Revista del Instituto de Historia del Derecho de la Facultad de Derecho y Ciencias Sociales, № 1, Buenos Aires, Imprenta de la Universidad, 1949.

MARTÍNEZ DÍAZ, Nelson, Anónimo. Noticias sobre el Río de la Plata: Montevideo en el siglo XVIII, Madrid, Historia 16, Colección Crónicas de América, 1988.

MORAES, María Inés, Las Economías Agrarias del Litoral Rioplatense en la segunda mitad del siglo XVIII: Paisajes y Desempeño, Tesis de Doctorado, Madrid, Universidad Complutense de Madrid, 2012.

PIMENTA, João Paulo, “¿A quién debería pertenecerle la banda oriental? Elementos para comprender la Independencia de Brasil a partir del Río de la Plata", Nuevo Mundo Mundos Nuevos, Debates 2013, consultado 28 abril 2015, disponible en: http:// nuevomundo.revues.org/65338;DOI:10.4000/ nuevomundo.65338.

"Província Oriental, Cisplatina, Uruguai: elementos para uma história da identidade oriental (1808-1828)", Marco PAMPLONA y María Elisa MÄDER (orgs.), Revoluções de independências e nacionalismo nas Américas: Região do Prata e Chile, São Paulo, Paz e Terra, 2007.

Estado y nación hacia el final de los imperios ibéricos: Río de la Plata y Brasil, 1808-1828, Buenos Aires, Sudamericana, 2011, pp. 57-58. 
PIVEL DEVOTO, Juan E., Raíces coloniales de la revolución oriental de 1811, Montevideo, Editorial Medina, 2da. Edición, 1957.

PORTILLO VALDÉS, J osé María, Crisis atlántica: autonomía e independencia en la crisis de la monarquía hispana, Madrid, Fundación Carolina-Marcial Pons, 2006.

SALA, Lucía, DE LA TORRE, Nelson y RODRÍGUEZ, J ulio, Estructura económicosocial de la Colonia. Montevideo, Ediciones Pueblos Unidos, 1967.

Evolución económica de la Banda Oriental. Montevideo, Ediciones Pueblos Unidos, 1968.

TAU ANZOÁTEGUI, Víctor, El taller del jurista. Sobre la Colección Documental de Benito de la Mata Linares, Oidor, Regente y Consejero de Indias, Madrid, Universidad Carlos III, 2011.

TEJ ERINA, Marcela, "La lucha entre España y Portugal por la ocupación del espacio: una valoración alternativa del Tratado de San Ildefonso de 1777", Revista de Historia, Departamento de História da Faculdade de Filosofia, Letras e Ciências Humanas, USP, 1996, № 135, pp. 31-40.

TORRE REVELLO, J osé, Documentos referentes a la historia argentina en la Real Academia de la Historia de Madrid, Buenos Aires, 1929.

\section{Fuentes}

"Noticias de los campos de Buenos Aires y Montevideo para su arreglo", RAHCML, Tomo LXXIV, $145 \mathrm{ff}$.

"Papel anónimo sobre arreglo de campos guardias y ganados de la otra Banda del Río de la Plata", RAH-CML, Tomo XIX, ff. 166-171.

Miguel de Lastarria, "Reorganización y Plan de Seguridad Exterior Colonias Orientales de las muy interesantes colonias orientales del rio Paraguay o de la Plata": http:// bdh.bne.es/bnesearch/biblioteca/ Reorganizaci\%C3\%B3n\%20y\%20pl an\%20de\%20seguridad\%20exterior\%20de\%20las\%20muy\%20interesantes \%20colonias\%20orientales\%20del\%20r\%C3\%ADo\%20Paraguay\%20o\%20d e\%20la\%20Plata\%20\%20\%20/ qls/ Lastarr\%C3\%ADa,\%20Miguel\%20de\%2 0(1759\%201827)/qls/bdh0000129957;jsessionid=CF2F1609090E529686F5 705610F5EAC4

Félix de Azara, "Memoria sobre el estado rural de Río de la Plata". Publicada en

Esteban CAMPAL, Azara y su legado al Uruguay, Montevideo, Ediciones de la Banda Oriental, 1969. 
Tratado de Madrid, 13 de enero de 1750: http:// www.cervantesvirtual.com/obravisor/tratado-firmado-en-madrid-a-13-de-enero-de-1750-para-determinarlos-limites-de-los-estados-pertenecientes-a-las-coronas-de-espana-yportugal-en-asia-y-america--0/html/ff8d40ae-82b1-11df-acc7002185ce6064 2.html

Tratado de San Ildefonso, 11 de octubre de 1777: http:// www.cervantesvirtual.com/obra-visor/tratado-preliminarsobre-los-limites-de-los-estados-pertenecientes-a-las-coronas-de-espana-yportugal-en-la-america-meridional-ajustado-y-concluido-en-san-lorenzo-a11-de-octubre-de-1777--0/html/ff8d38fc-82b1-11df-acc7002185ce6064_1.html 